\title{
Article \\ Prediction of Unplanned Hospitalizations in Older Patients Treated with Chemotherapy
}

\author{
Jaime Feliu ${ }^{1, *(\mathbb{C})}$, Enrique Espinosa ${ }^{1}$, Laura Basterretxea ${ }^{2}$, Irene Paredero ${ }^{3}{ }^{\mathbb{D}}$, Elisenda Llabrés ${ }^{4}$, \\ Beatriz Jiménez-Munárriz ${ }^{5}$, Beatriz Losada ${ }^{6}{ }^{-}$, Alvaro Pinto ${ }^{1}$, Ana Belén Custodio ${ }^{1}$, María del Mar Muñoz ${ }^{7}$, \\ Jeniffer Gómez-Mediavilla ${ }^{2}$, María Dolores Torregrosa ${ }^{3}$, Patricia Cruz ${ }^{1}$, Oliver Higuera ${ }^{1}$ \\ and María José Molina-Garrido ${ }^{7}$
}

check for updates

Citation: Feliu, J.; Espinosa, E.; Basterretxea, L.; Paredero, I.; Llabrés, E.; Jiménez-Munárriz, B.; Losada, B.; Pinto, A.; Custodio, A.B.; Muñoz, M.d.M.; et al. Prediction of Unplanned Hospitalizations in Older Patients Treated with Chemotherapy. Cancers 2021, 13, 1437. https://doi.org/ 10.3390/cancers13061437

Academic Editor:

Dimitrios Mavroudis

Received: 23 January 2021

Accepted: 19 March 2021

Published: 22 March 2021

Publisher's Note: MDPI stays neutral with regard to jurisdictional claims in published maps and institutional affiliations.

Copyright: (c) 2021 by the authors. Licensee MDPI, Basel, Switzerland. This article is an open access article distributed under the terms and conditions of the Creative Commons Attribution (CC BY) license (https:// creativecommons.org/licenses/by/ $4.0 /)$.
1 Oncology Department, Hospital Universitario La Paz. IDIPAZ, Cátedra UAM-AMGEN, Centro de Investigación Biomédica en Red de Cáncer, 28046 Madrid, Spain; eespinosa@salud.madrid.org (E.E.); alvaro.pinto@salud.madrid.org (A.P.); ana.custodio@salud.madrid.org (A.B.C.); patricia.cruz@salud.madrid.org (P.C.); oliver.higuera@salud.madrid.org (O.H.)

2 Oncology Department, Hospital Universitario de Donostia, 20014 Donostia, Spain; laura.basterrecheabadiola@osakidetza.eus (L.B.); jgomez@onkologikoa.org (J.G.-M.)

3 Oncology Department, Hospital Universitario Dr. Peset, 46017 Valencia, Spain; irene.paredero@hospitalprovincial.es (I.P.); m.dolores.torregrosa@uv.es (M.D.T.)

4 Oncology Department, Hospital Universitario Insular de Gran Canarias, 35016 Las Palmas, Spain; ellaval@gobiernodecanarias.org

5 Oncology Department, Centro Integral Oncológico Clara Campal, 28050 Madrid, Spain; bjimenez@hmhospitales.com

6 Oncology Department, Hospital Universitario de Fuenlabrada, 28942 Fuenlabrada, Spain; beatriz.losada@salud.madrid.org

7 Oncology Department, Hospital Virgen de la Luz, 16002 Cuenca, Spain; madelms@sescam.jccm.es (M.d.M.M.); mjmolinag@sescam.jccm.es (M.J.M.-G.)

* Correspondence: jaime.feliu@salud.madrid.org; Tel./Fax: +3-491-727-7118

Simple Summary: Unplanned hospitalizations (UHs) are common among elderly patients with cancer who receive chemotherapy. This fact decreases quality of life or performance status and increases health costs. Our objective was to determine predictive factors for UH in this population. A score based on six variables taken from geriatric assessment and chemotherapy characteristics was developed in a series of 493 elderly patients receiving chemotherapy. The use of this score may reliably identify patients at risk for $\mathrm{UH}$, thus helping to plan treatment, implement adaptive measures, and set up a close follow-up schedule.

Abstract: Purpose: To determine the incidence of unplanned hospitalization (UH) and to identify risk factors for UH in elderly patients with cancer who start chemotherapy. Methods: In all, 493 patients over 70 years starting new chemotherapy regimens were prospectively included. A pre-chemotherapy geriatric assessment was performed, and tumor and treatment variables were collected. The association between these factors and UH was examined by using multivariable logistic regression. Score points were assigned to each risk factor. Results: During the first 6 months of treatment, 37\% of patients had at least one episode of UH. Risk factors were the use of combination chemotherapy at standard doses, a MAX2 index $\geq 1$, a Charlson comorbidity score $\geq 2$, albumin level $<3.5 \mathrm{~g} / \mathrm{dL}$, falls in the past 6 months $\geq 1$, and weight loss $>5 \%$. Three risk groups for $\mathrm{UH}$ were established according to the score in all patients: $0-1: 17.5 \% ; 2$ : $34 \%$; and 3-7: $57 \%(p<0.001)$. The area under receiver operation characteristic (ROC) curve was 0.72 (95\% CI: 0.67-0.77). Conclusion: This simple tool can help to reduce the incidence of $\mathrm{UH}$ in elderly patients with cancer who are scheduled to initiate chemotherapy treatment.

Keywords: older patient; unplanned hospitalizations; risk score; geriatric assessment; chemotherapy 


\section{Introduction}

Chemotherapy may benefit quality of life in elderly patients with cancer through increased survival and symptom relief [1,2], but aging also favors the appearance of severe toxicities and other complications such as the worsening of preexisting conditions [3]. An undesirable consequence of antineoplastic treatments in the elderly is the increase in hospital admissions, since it may have a significant impact on the patient's quality of life, causing an irreversible decline in functional capacity and loss of independence and leading to institutionalization in many cases [4,5]. Hospitalization is a costly [6] and distressing experience for patients with cancer and their families. Moreover, as elderly people usually prioritize quality over quantity of life, hospitalization may interfere with patients' stated preferences.

Up to $35 \%$ of patients with cancer have an unplanned hospitalization $(\mathrm{UH})$ during the first year following diagnosis. This percentage rises to $42.5 \%$ in those older than 75 [7].

Chemotherapy-derived toxicity accounts for $30-40 \%$ of hospitalization events in cancer patients [8], and an estimated $9 \%$ of patients receiving chemotherapy need hospitalization for that reason [9]. UH in the elderly can be the result of toxicity, worsening of cancer symptoms or worsening of comorbidities as a consequence of cancer or its treatment. A recent study including 8451 cancer patients aged $\geq 70$ reported an incidence of $\mathrm{UH}$ of $20 \%$ in the next three months following the initiation of therapy [10].

Few studies have focused on older adults with cancer, and risk factors associated with UH are not well defined. Critical factors in younger adults are comorbidity [7,8], as well as renal and bone marrow function [8]. Additional factors such as age and Eastern Cooperative Oncology Group (ECOG) performance status have been described in older patients [11]. Some studies have assessed the value of the geriatric assessment (GA) or its components to predict $\mathrm{UH}$, with conflicting results. One study could not correlate GA with the risk of UH [12], whereas others have identified some related factors, such as dependency in instrumental activities of daily living (IADL) or in activities of daily living (ADL), malnutrition, presence of comorbidities, abnormal G8 [10], or reduced gait speed [13].

Previous studies in this setting included older patients receiving either chemotherapy or just palliative supportive care [7,10] or were focused on hematologic malignancies [13]. The identification of factors predicting $\mathrm{UH}$ in the older patients receiving chemotherapy could be used to set up adaptive or aggressive supportive measures around the time of chemotherapy initiation to prevent UH. It would also select patients in whom the chemotherapy schemes should be modified to reduce the risk of toxicity and would improve the chemotherapy informed-consent process. Finally, it could contribute to improve quality of life and quality of care and to reduce health care costs (provided this leads to directed interventions).

The objective of this study was to determine the incidence of UH and associated risk factors in older patients (age $\geq 70$ years) with cancer who start chemotherapy.

\section{Results}

\subsection{Patient and Tumor Characteristics}

Among the 551 patients who completed baseline assessment, three patients moved to another center after the first cycle of treatment, two died from rapidly progressing cancer prior to treatment, two patients withdrew consent early, and four were treated with targeted therapies without chemotherapy and were excluded from the analysis. Information about $\mathrm{UH}$ was not provided by treating centers in 47 patients, so the series finally included 493 patients.

Baseline patient characteristics, including demographics, GA, chemotherapy, and laboratory findings, are shown in Table 1 . Median age was 77 years (range 70-92, 35\% were $\geq 80$ years); most patients had a good performance status with ECOG $\leq 1(87 \%)$, staging was I-III ( $42 \%)$ and IV (58\%). The most common tumor types were gastrointestinal $(52 \%)$, genitourinary $(13 \%)$, lung $(12 \%)$, and breast $(6 \%)$. Fifty-nine percent of patients 
received polychemotherapy, $44 \%$ received standard doses of chemotherapy. Chemotherapy was administered in the adjuvant or neoadjuvant setting in $37 \%$ of patients, as first line in $54 \%$, and as second or subsequent line in $9 \%$. Primary prophylaxis with granulocyte colony-stimulating factor growth factors was used in $14 \%$ of patients. Thirty-two percent of patients received concurrent chemotherapy and radiation therapy.

Table 1. Patient characteristics $(n=493)$.

\begin{tabular}{|c|c|}
\hline Characteristic & Patients, $n(\%)$ \\
\hline \multicolumn{2}{|l|}{ Age } \\
\hline $70-74$ & $169(34 \%)$ \\
\hline $75-79$ & $152(31 \%)$ \\
\hline$\geq 80$ & $172(35 \%)$ \\
\hline \multicolumn{2}{|l|}{ Sex } \\
\hline Male & $310(63 \%)$ \\
\hline Female & $183(37 \%)$ \\
\hline \multicolumn{2}{|l|}{ Tumor site } \\
\hline Gastrointestinal & $256(52)$ \\
\hline Genitourinary & $64(13)$ \\
\hline Lung & $59(12)$ \\
\hline Breast & $30(6)$ \\
\hline Gynecologic & $15(3)$ \\
\hline Other & $69(14)$ \\
\hline \multicolumn{2}{|l|}{ Metastatic status } \\
\hline M0 & $209(42 \%)$ \\
\hline M1 & $284(58 \%)$ \\
\hline \multicolumn{2}{|l|}{ ECOG PS } \\
\hline 0 & $126(25 \%)$ \\
\hline 1 & $304(62 \%)$ \\
\hline 2 & $63(13 \%)$ \\
\hline \multicolumn{2}{|l|}{ IADL } \\
\hline 8 & $217(44 \%)$ \\
\hline$\leq 7$ & $276(56 \%)$ \\
\hline \multicolumn{2}{|l|}{$\mathrm{ADL}$} \\
\hline 6 & $387(79 \%)$ \\
\hline$\leq 5$ & $106(21 \%)$ \\
\hline \multicolumn{2}{|l|}{ Number of falls in the past 6 months } \\
\hline None & $409(83 \%)$ \\
\hline$\geq 1$ & $85(17 \%)$ \\
\hline \multicolumn{2}{|l|}{ Charlson comorbidity score } \\
\hline 0 & $166(34 \%)$ \\
\hline 1 & $142(29 \%)$ \\
\hline$\geq 2$ & $185(37 \%)$ \\
\hline \multicolumn{2}{|l|}{ VES-13 } \\
\hline $0-2$ & $171(35 \%)$ \\
\hline$\geq 3$ & $322(65 \%)$ \\
\hline \multicolumn{2}{|l|}{ Chemotherapy } \\
\hline Standard therapy & $215(44 \%)$ \\
\hline Reduced therapy or monotherapy & $278(56 \%)$ \\
\hline \multicolumn{2}{|l|}{ MAX2 index } \\
\hline 0 & $151(31 \%)$ \\
\hline 1 & $292(59 \%)$ \\
\hline 2 & $50(10 \%)$ \\
\hline
\end{tabular}

Abbreviations: ECOG PS: Eastern Cooperative Oncology Group performance status. ADL: activity of daily living, IADL: instrumental activity of daily living, VES-13: Vulnerable Elders Survey-13.

The GA detected that $15 \%$ of patients lived alone and $75 \%$ had less than an associate/bachelor's degree. According to the Charlson comorbidity index, 37\% of patients had comorbidity greater than or equal to grade 2 , and $22 \%$ and $44 \%$ were dependent on ADL and IADL scales, respectively. Impairment of cognitive function was detected in $11 \%$ 
of the patients. Thirteen percent had a low body mass index of less than $22 \mathrm{~kg} / \mathrm{m}^{2}$, and $50 \%$ had a score $\geq 3$ according to the Vulnerable Elders Survey-13.

\subsection{Incidence and Reasons of Unplanned Hospitalizations}

After a follow-up of 6 months, 184/493 patients (37\%) had had at least one UH. There was one episode in $72 \%(132 / 184)$, two in $21 \%(39 / 184)$, three in $3 \%(12 / 184)$, and four in $0.5 \%(1 / 184)$. Most patients $(133 / 184,72 \%)$ had the first UH in the first 3 months (Figure 1 ). Table 2 outlines the causes of UH, the most common being for cancer-related reasons $(29 \%)$, chemotherapy toxicity $(19 \%)$, and infections (either in the lungs, $16 \%$, or somewhere else, $12 \%)$.

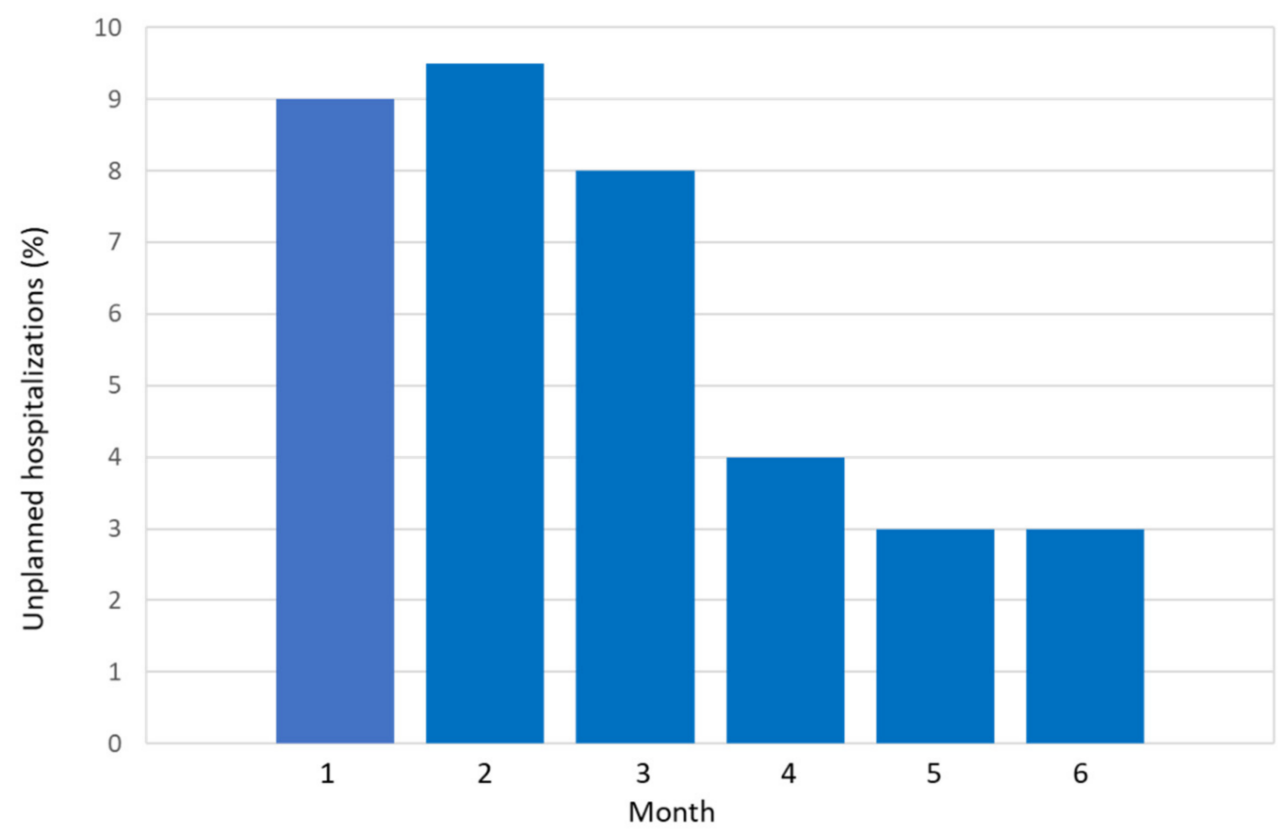

Figure 1. Percentage of unplanned hospitalizations by month.

Table 2. Reasons for the first unplanned hospitalization in older patients with cancer treated with chemotherapy $(n=184)$.

\begin{tabular}{cc}
\hline Reported Cause & $\boldsymbol{n} \mathbf{( \% )}$ \\
\hline Cancer related & $53(29)$ \\
\hline Chemotherapy toxicity & $37(19)$ \\
\hline Lung infection & $30(16)$ \\
\hline Other infections & $22(12)$ \\
\hline Falls and fractures & $13(7)$ \\
\hline Cardiac events & $9(5)$ \\
\hline Thromboembolic events & $7(4)$ \\
\hline Neurological events & $5(3)$ \\
\hline Hemorrhage/bleedings & $4(2)$ \\
\hline Gastrointestinal events & $4(2)$ \\
\hline Falls & $2(1)$ \\
\hline
\end{tabular}

\subsection{Predictive Variables Associated with Unplanned Hospitalizations in the First 6 Months}

In the univariable analysis, we identified 11 factors that were associated with $\mathrm{UH}$ (Table 3). The risk factors associated with 6-month $\mathrm{UH}$ in univariable analysis $(p<0.05)$ 
and variables deemed to be of clinical importance (i.e., age and tumor subtype) were included in the multivariable analysis. In the multivariable model, only six independent variables were directly associated with a higher risk of UH (Table 4): the administration of standard-dose combination chemotherapy, a MAX2 index $\geq 1$, a Charlson comorbidity score $\geq 2$, albumin level $<3.5 \mathrm{~g} / \mathrm{dL}$, falls in the past 6 months $\geq 1$, and unintended weight loss $>5 \%$.

Table 3. Factors associated with unplanned hospitalizations on univariable analysis.

\begin{tabular}{|c|c|c|c|c|}
\hline Variable & $\begin{array}{c}\mathrm{UH}(n=184) \\
n \%\end{array}$ & $\begin{array}{c}\text { Non-UH } \\
(n=309) \\
n \%\end{array}$ & OR $(95 \%$ CI) & $p$ Value \\
\hline \multicolumn{5}{|l|}{ Stage } \\
\hline IV & $118(64)$ & $166(56)$ & $1.54(1.06-2.24)$ & 0.024 \\
\hline I-III & $66(36)$ & $143(44)$ & & \\
\hline \multicolumn{5}{|l|}{ MAX2 index } \\
\hline$\geq 1$ & $138(75)$ & $205(66)$ & $1.52(1.02-2.29)$ & 0.044 \\
\hline 0 & $46(25)$ & $104(34)$ & & \\
\hline \multicolumn{5}{|l|}{ Chemotherapy } \\
\hline Standard therapy & $98(53)$ & $117(38)$ & $1.91(1.32-2.76)$ & 0.001 \\
\hline Reduced/monotherapy & $86(47)$ & $192(62)$ & & \\
\hline \multicolumn{5}{|l|}{ Albumin g/dL } \\
\hline$\leq 3.5$ & $51(28)$ & $30(10)$ & $3.61(2.21-5.92)$ & $<0.001$ \\
\hline$>3.5$ & $133(72)$ & $279(90)$ & & \\
\hline \multicolumn{5}{|l|}{$\begin{array}{l}\text { Creatinine Clearance } \\
\mathrm{mL} / \mathrm{min}\end{array}$} \\
\hline$<50$ & $87(47)$ & $106(34)$ & $1.75(1.20-2.54)$ & 0.03 \\
\hline$\geq 50$ & $97(53)$ & $203(66)$ & & \\
\hline \multicolumn{5}{|l|}{ Unintentional weight loss \% } \\
\hline$>5 \%$ & $80(43)$ & $69(22)$ & $2.67(1.80-3.97)$ & $<0.001$ \\
\hline$\leq 5 \%$ & $104(57)$ & $240(78)$ & & \\
\hline \multicolumn{5}{|l|}{ ECOG PS } \\
\hline 2 & $35(19)$ & $28(9)$ & $2.36(1.38-4.03)$ & 0.02 \\
\hline $0-1$ & $149(81)$ & $280(91)$ & & \\
\hline \multicolumn{5}{|l|}{ Charlson comorbidity score } \\
\hline$\geq 2$ & $84(45)$ & $101(33)$ & $1.73(1.18-2.51)$ & 0.004 \\
\hline $0-1$ & $100(55)$ & $208(67)$ & & \\
\hline \multicolumn{5}{|l|}{ ADL } \\
\hline$\leq 5$ & $52(28)$ & $54(17)$ & $1.87(1.21-2.89)$ & 0.005 \\
\hline 6 & $132(72)$ & $255(83)$ & & \\
\hline \multicolumn{5}{|l|}{ IADL } \\
\hline$\leq 7$ & $87(47)$ & $187(60)$ & $1.71(1.18-2.47)$ & 0.004 \\
\hline 8 & $97(53)$ & $122(40)$ & & \\
\hline \multicolumn{5}{|l|}{ Falls in the past 6 months } \\
\hline$\geq 1$ & $45(24)$ & $39(13)$ & $2.24(1.39-3.60)$ & 0.01 \\
\hline None & $139(76)$ & $270(87)$ & & \\
\hline
\end{tabular}


Table 4. Variables significantly associated with unplanned hospitalizations on multivariable analysis.

\begin{tabular}{cccccc}
\hline Variable & $\boldsymbol{\beta}$ & SE & $p+$ & OR (95\% CI) & Score \\
\hline Standard therapy & 0.475 & 0.211 & 0.24 & $1.608(1.064-2.431)$ & 1 \\
\hline MAX2 index $\geq 1$ & 0.558 & 0.215 & 0.02 & $1.748(1.093-2.796)$ & 1 \\
\hline Weight loss $>5 \%$ & 0.659 & 0.234 & 0.005 & $1.933(1.222-3.059)$ & 1 \\
\hline Albumin $\leq 3.5 \mathrm{~g} / \mathrm{dL}$ & 0.934 & 0.286 & 0.01 & $2.545(1.453-4.456)$ & 2 \\
\hline Charlson score $\geq 2$ & 0.471 & 0.215 & 0.029 & $1.601(1.050-2.440)$ & 1 \\
\hline $\begin{array}{c}\text { Falls in the past } 6 \\
\text { months } \geq 1\end{array}$ & 0.614 & 0.268 & 0.022 & $1.847(1.093-3.123)$ & 1
\end{tabular}

$\overline{\mathrm{CI}}=$ confidence interval; $\mathrm{OR}=$ odds ratio; $+p$ values were calculated using a two-sided Wald test for multivariable analyses.

The risk score was applied to each patient, and patients were classified into three categories on the basis of the risk of UH: low risk (0-1 points: $17.5 \%$ 6-month UH rate), intermediate risk (2 points: $34 \%$ 6-month $\mathrm{UH}$ rate), and high risk (3-7 points: 57\% 6-month $\mathrm{UH}$ rate). The proportion of patients classified as low, intermediate, or high risk were $32 \%$, $30 \%$, and $38 \%$, respectively (Figure 2). There was a significant difference in the mortality within the first 6 months among the risk groups $(p<0.001)$.

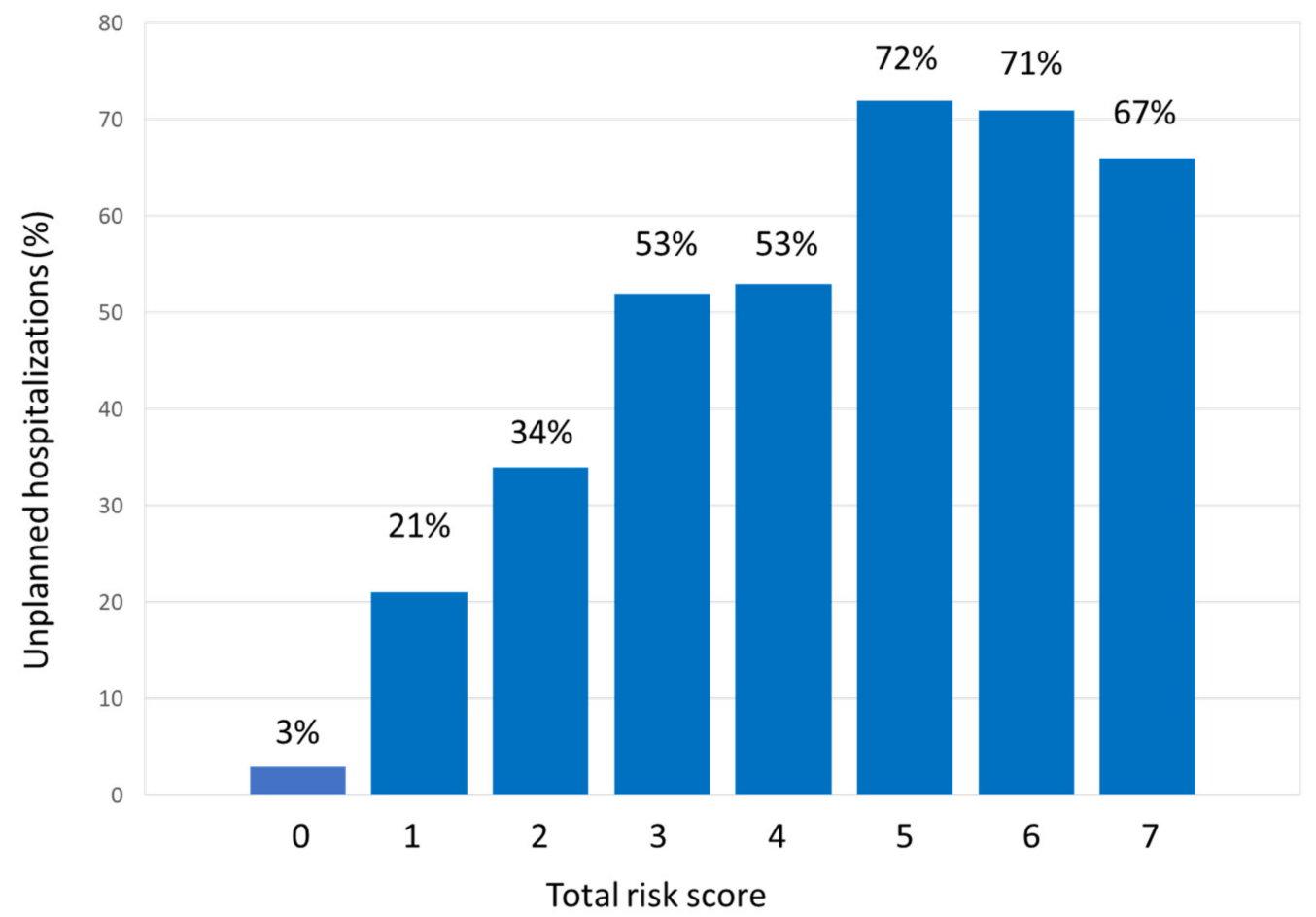

Figure 2. Ability of risk score to predict unplanned hospitalizations in the next 6 months.

The area under receiver operation characteristic (ROC) curve was 0.72 (95\% CI: 0.67-0.77) (Supplementary Figure S1). Exploratory analyses were performed to calculate the model performance of the total risk score according to stage (localized 0.71 and disseminated 0.73), and for each tumor type: (GI 0.70, GU 0.78, breast 0.68, lung 0.61, another cancer 0.89). Calibration of the final model was assessed by the Hosmer-Lemeshow goodness of fit test. A $p$-value of $0.49(95 \% \mathrm{CI}, 0.45-0.53)$, suggests that the model is accurate.

\section{Discussion}

Over one-third of patients in our series had a UH in the 6 months following the start of chemotherapy. This complication is particularly relevant in the elderly because 
of its impact on quality of life and of the risk that hospitalization leads to an irreversible decline in functional capacity and loss of independence. Hospitalization also increases health costs, estimated at $48 \%$ of the cost of medical care of patients with advanced tumors [14]. The identification of risk factors for UH could lead to the implementation of preventive measures.

The factors predicting UH in our population can be easily obtained as they are gathered in daily practice. Some of them are related to the treatment itself, whereas others are part of the GA: nutritional status (albumin and weight loss), performance status (falls), and comorbidity (Charlson index). All these factors relate with some of the conditions known to cause UH in older patients: chemotherapy toxicity, comorbidity, and frailty.

The risk of developing grade 3-4 toxicity has been previously correlated with standarddose combination chemotherapy [8,15-17] and treatment aggressiveness (MAX2 index) [17]. Falls have also been identified as a risk factor for increased toxicity [16]. On the other hand, some studies have found that comorbidity [8-11,18], chemotherapy, poor nutritional status [10], and low albumin level $[8,19]$ increase the risk of UH. Serum albumin decreases $15-20 \%$ with age, even more in patients with poor nutrition. This may result in an increase in the free fraction of the drug in plasma, as described with cisplatin, etoposide, taxanes, or methotrexate [20], thus increasing adverse events.

Unlike other studies $[10,13,17]$, we did not find an association of UH with poor ECOG performance status, ADL, or gait speed in the multivariate analysis. However, the history of falls was significant. This factor relates not only to the functional status but also to the risk of chemotherapy toxicity [16]. The role of age is controversial. We and others [10] did not find a direct correlation, although two studies performed in the community population and in patients with colon cancer, found a correlation of UH with advanced age $[17,21]$. Finally, one study reported less risk of UH in the elderly, probably due to the use of less-aggressive treatment [8].

Of note, $87 \%$ of patients had an ECOG performance status $\leq 1$. This is higher than that reported in other studies [10] and could have biased the results. The good condition in our patients derives from the fact that only those amenable for chemotherapy were included, whereas other studies also included patients receiving just supportive care [10].

To our knowledge, this is the first prognostic score to address the risk of UH in older patients with cancer who are going to initiate chemotherapy. The score is simple, easy to implement, and reliable in identifying groups of patients with different risk of $\mathrm{UH}$. Although three risk groups were established, risk increases with score also within the group. Therefore, in the high-risk group (score 3-7 points) there is a $57 \%$ 6-month $\mathrm{UH}$ rate, but this percentage rises to $71 \%$ in patients with $5-7$ points.

The identification of patients at increased risk for UH may guide specific intervention, for instance, the use of less toxic schemes, reduced doses, or single-agent therapy, particularly in patients receiving therapy with palliative intent. However, if therapy is used with curative intent, careful consideration should be taken as dose modification could reduce efficacy. Likewise, measures could be initiated to improve the nutritional and functional status of older patients, although the randomized study GAIN (Geriatric assessment-driven intervention) showed that such measures only reduce drug toxicity but not UH or the number of visits to the emergency department [22]. Supportive care and close monitoring should be established in high-risk patients.

The strengths of this study are its multicenter design and the development of a score that is simple and easy to use. Regarding its limitations, (1) patients with hematological malignancies were not included, so the utility in this population remains unknown; (2) there is no external validation, so we do not know whether the score could be used in a different population; (3) the score predicts UH in the first 6 months of therapy but not beyond that time. However, most UHs happen in the first 3 months [9]; (4) the score was developed in older patients receiving chemotherapy, so we do not know its validity in those receiving other treatment such as immunotherapy or targeted therapies. 
The present study indicates that a score based on six variables taken from geriatric assessment and chemotherapy characteristics may reliably identify older patients at risk for UH. The use of this simple tool could help to plan treatment and establish interventions and recommendations to decrease risks in this population.

\section{Patients and Methods}

\subsection{Patients}

This prospective and multicenter study was performed in eight hospitals in Spain between February 2014 and June 2018. The main objective was to assess factors predicting the occurrence of grade 3-4 toxicity in older patients who received chemotherapy [14]. Patients aged $\geq 70$ years with histological or cytological confirmation of malignancy in any stage were included. Other inclusion criteria were as follows: (1) initiation of a new chemotherapy regimen, (2) the ability to read Spanish (questionnaires for geriatric assessment were in Spanish), and (3) outpatient condition. All patients provided written informed consent to participate in the study. The study was approved by the institutional review board at each participating institution.

Here, we present a sub-study focusing on the incidence of UH and associated risk factors in older patients with a solid cancer, within 6 months from the start of chemotherapy. A UH was defined as any inpatient admission to an acute care hospital that began after the day of starting chemotherapy and that could not be foreseen. It may occur on a nonemergency or an emergency basis [23]. Data on unplanned hospitalizations were collected retrospectively.

\subsection{Study Schema}

Clinical staging was performed according to routine clinical practice depending on each cancer type. Patients completed GA before the start of chemotherapy. This assessment included a standardized evaluation of their social support and comorbidity, as well as their functional, cognitive, psychological, and nutritional status (Table S1). The questionnaire was delivered by a research nurse; one part was completed by the patient and another one by the health professional. The latter included the following items: comorbidities (collected using the Charlson comorbidity index) [24], Eastern Cooperative Oncology Group performance status [25], Short Physical Performance Battery (gait speed, chair rise, and progressive Romberg) [26,27], the body mass index, and the Pfeiffer test [28]. The Pfeiffer test or Short Portable Mental Status Questionnaire (SPMS) is an easily administered, validated, 10-item screen for cognitive impairment that has been tested in clinical and institution-based samples. Test-retest reliability was $\geq 0.82$, and the agreement between the SPMS and clinical diagnosis for intact cognition or mild impairment was $82 \%$. It has been established that three or more mistakes suggest cognitive impairment and advise a thorough study of cognitive function, always taking cultural and study levels into consideration. The patient part consisted of self-reported measures of functional status: activities of daily living (ADL) [29], instrumental activities of daily living (IADL) [30], number of falls in the last 6 months, nutrition, medications, psychological state [31], social support/function [32,33], and ability to take medications unassisted. A member of the healthcare team assisted those who needed help with completing the questionnaires.

The following variables were collected in addition to the results of the GA: age, gender, marital status, household composition, education, cancer subtype and stage, and selected blood tests obtained before treatment (hemoglobin, white blood cell count, platelets, creatinine, albumin, liver function test, and creatinine clearance [34]). Data regarding the type of chemotherapy, line of treatment, and use of granulocyte-growth factors were also recorded.

The risk of chemotherapy-induced toxicity for every chemotherapy regimen administered was estimated with the MAX2 index toxicity [35]. The MAX2 index summarizes the overall risk of severe chemotherapy-induced toxicity based on an average study using data from published clinical trials. Briefly, the MAX2 index is the average of the highest frequency of both grade 4 hematologic toxicity and grade $3 / 4$ non-hematologic toxicity, 
with higher scores indicating higher risk of toxicity. It is reproducible across cancer types and studies, and it is sensitive to toxicity differences among chemotherapy regimens.

Patients were prospectively followed until the end of the chemotherapy course. UHs occurring in the 6 months following the start of treatment were recorded.

\subsection{Statistical Analysis}

The primary outcome was the occurrence of UH within 6 months after the start of treatment. Descriptive statistics characterizing patient groups were provided. The $X^{2}$ test was used to examine the association between UH and categorical variables and independent $\mathrm{t}$ tests for continuous variables.

We performed a correlation assessment using the Spearman's rho test as appropriate for categorical variables. Multicollinearity between variables was defined as a rho test value $\geq 0.50$. An evaluation of $\mathrm{UH}$ predictors was performed by using logistic regression. Univariate models were first fitted for all prognostic factors. Significant variables at the $5 \%$ level were selected for inclusion in the multivariable model. Odds ratios (ORs) were reported with their $95 \%$ CIs. $p<0.05$ was considered statistically significant for all comparisons. The optimal cut-point for the continuous variables was determined using the Youden index, and the categorical variables were dichotomized according to clinically relevant cutoffs. The amount of accounted variance was determinate with the Nagelkerke correlation coefficient $\left(\mathrm{R}^{2}\right)$. Model calibration and discrimination were assessed by the Hosmer-Lameshow test and the area under the receiver operating characteristic (ROC) curve [36,37]. For the development of the score, each factor was assigned a particular score based on its $\beta$ coefficient. The $\beta$ coefficient for each risk factor was divided by the lowest $\beta$ coefficient and rounded to the nearest whole number $[38,39]$. The risk score was then applied to each patient. The sample was divided into three risk strata (low, medium, and high risk of $\mathrm{UH}$ ) on the basis of approximate tertiles of risk score. We compared UH within the first 6 months among the risk groups by chi square testing. We used the bootstrap method (1000 repetitions) for internal validation of the risk score. Bootstrap validation is a method of random resampling from a given set of samples to simulate the effect of drawing samples from the same population.

Analyses were carried out by with SPSS software (version 18; SPSS, Chicago, IL, USA).

\section{Conclusions}

A risk score to predict UH in elderly patients receiving chemotherapy was developed. The score combines data from the GA and the characteristics of chemotherapy. This tool may help in treatment planning and in the implementation of measures aimed at improving the care of our patients and reducing $\mathrm{UH}$.

Supplementary Materials: The following are available online at https://www.mdpi.com/2072 $-6694 / 13 / 6 / 1437 / s 1$, Figure S1: Receiver operating characteristic (ROC) analyses to assess the capacity of the prognostic score to predict 6-month unplanned hospitalizations, Table S1: Summary of comprehensive geriatric assessment domains and elements.

Author Contributions: Conceptualization: J.F., E.E., B.J.-M., M.D.T., and M.J.M.-G.; methodology: J.F. and E.E.; provision of study material or patients: J.F., E.E., L.B., I.P., E.L., B.J.-M., B.L., A.P., A.B.C., M.d.M.M., J.G.-M., M.D.T., P.C., O.H., and M.J.M.-G.; formal analysis: J.F. and E.E.; investigation J.F. and E.E.; data curation: J.F. and E.E.; writing—original draft preparation: J.F. and E.E.; writingreview and editing: J.F., E.E., L.B., I.P., E.L., B.J.-M., B.L., A.P., A.B.C., M.d.M.M., J.G.-M., M.D.T., P.C., O.H., and M.J.M.-G.; visualization J.F.; supervision J.F.; project administration: J.F. All authors have read and agreed to the published version of the manuscript.

Funding: This research received no external funding.

Institutional Review Board Statement: The names of the Ethics Committees that approved the study, along with the number/ID of the approvals are: Comite Ético del H. Universitario del H. La Paz (IRB number: 1349). Comité Ético del H. Universitario del Hospital OSI Bilbao Basurto (IRB number: 0318). Hospital Universitario Dr. Peset. (IRB number: 0031/6). Comité Ético del H. 
Universitario del Complejo Hospitalario Universitario Insular-Materno Infantil (IRB number: 9161). Comité Ético del H. Universitario del Hospital Universitario de Fuenlabrada (IRB number: 10123). Comité Ético del H. Universitario del Institut Català d'Oncologia. (IRB number: 0028/13). Comité Ético del H. Universitario del Hospital Virgen de La Luz Hospital (IRB number: 1712).

Informed Consent Statement: Informed consent was obtained from all subjects involved in the study.

Data Availability Statement: De-identified individual data might be made available following publication by reasonable request to the corresponding author.

Conflicts of Interest: The authors declare no conflict of interest.

\section{References}

1. Haller, D.G.; O'Connell, M.J.; Cartwright, T.H.; Twelves, C.J.; McKenna, E.F.; Sun, W.; Saif, M.W.; Lee, S.; Yothers, G.; Schmoll, H.-J. Impact of age and medical comorbidity on adjuvant treatment outcomes for stage III colon cancer: A pooled analysis of individual patient data from four randomized, controlled trials. Ann. Oncol. 2015, 26, 715-724. [PubMed]

2. Langer, C.J.; Manola, J.; Bernardo, P.; Kugler, J.W.; Bonomi, P.; Cella, D.; Johnson, D.H. Cisplatin-based therapy for elderly patients with advanced non-small-cell lung cancer: Implications of Eastern Cooperative Oncology Group 5592, a randomized trial. J. Natl. Cancer Inst. 2002, 94, 173-181. [CrossRef] [PubMed]

3. Feliu, J.; Heredia-Soto, V.; Gironés, R.; Jiménez-Munarriz, B.; Saldaña, J.; Guillén-Ponce, C.; Molina-Garrido, M.J. Management of the toxicity of chemotherapy and targeted therapies in elderly cancer patients. Clin. Transl. Oncol. 2020, 22, 457-467. [CrossRef]

4. Creditor, M.C. Hazards of hospitalization of the elderly. Ann. Intern Med. 1993, 118, 219-223. [CrossRef] [PubMed]

5. Sager, M.A.; Franke, T.; Inouye, S.K.; Landefeld, C.S.; Morgan, T.M.; Rudberg, M.A.; Sebens, H.; Winograd, C.H. Functional outcomes of acute medical illness and hospitalization in older persons. Arch Intern. Med. 1996, 156, 645-652. [CrossRef] [PubMed]

6. Yabroff, K.R.; Lamont, E.B.; Mariotto, A.; Warren, J.L.; Topor, M.; Meekins, A.; Brown, M.L. Cost of care for elderly cancer patients in the United States. J. Natl. Cancer Inst. 2008, 100, 630-641. [CrossRef] [PubMed]

7. Whitney, R.L.; Bell, J.F.; Tancredi, D.J.; Romano, P.S.; Bold, R.J.; Wun, T.; Joseph, J.G. Unplanned hospitalization among individuals with cancer in the year after diagnosis. J. Oncol. Pract. 2019, 15, e20-e29. [CrossRef] [PubMed]

8. Brooks, G.A.; Kansagra, A.J.; Rao, S.R.; Weitzman, J.I.; Linden, E.A.; Jacobson, J.O. A clinical prediction model to assess risk for chemotherapy related hospitalization in patients initiating palliative chemotherapy. JAMA Oncol. 2015, 1, 441-447. [CrossRef]

9. Hassett, M.J.; Rao, S.R.; Brozovic, S.; Stahl, J.E.; Schwartz, J.H.; Maloney, B.; Jacobson, J.O. Chemotherapy-related hospitalization among community cancer center patients. Oncologist 2011, 16, 378-387. [CrossRef]

10. Lodewijckx, E.; Kenis, C.; Flamaing, J.; Debruyne, P.; De Groof, I.; Focan, C.; Cornélis, F.; Verschaeve, V.; Bachmann, C.; Bron, D.; et al. Unplanned hospitalizations in older patients with cancer: Occurrence and predictive factors. J. Geriatr. Oncol. 2020, 19. [CrossRef]

11. Puts, M.T.E.; Monette, J.; Girre, V.; Wolfson, C.; Monette, M.; Batist, G.; Bergman, H. Does frailty predict hospitalization, emergency department visits, and visits to the general practitioner in older newly-diagnosed cancer patients? Results of a prospective pilot study. Crit. Rev. Oncol. Hematol. 2010, 76, 142-151. [CrossRef]

12. Liu, M.A.; DuMontier, C.; Murillo, A.; Hshieh, T.T.; Bean, J.F.; Soiffer, R.J.; Stone, R.M.; Abel, G.A.; Driver, J.A. Gait speed, grip strength, and clinical outcomes in older patients with hematologic malignancies. Blood 2019, 134, 374-382. [CrossRef]

13. Brooks, G.A.; Li, L.; Uno, H.; Hassett, M.J.; Landon, B.E.; Schrag, D. Acute hospital care is the chief driver of regional spending variation in Medicare patients with advanced cancer. Health Aff. 2014, 33, 1793-1800. [CrossRef]

14. Feliu, J.; Jiménez-Munárriz, B.; Basterretxea, L.; Paredero, I.; Llabrés, E.; Antonio-Rebollo, M. Predicting Chemotherapy Toxicity in Older Patients with Cancer: A Multicenter Prospective Study. Oncologist 2020, 25, e1516-e1524. [CrossRef]

15. Hurria, A.; Togawa, K.; Mohile, S.G.; Owusu, C.; Klepin, H.D.; Gross, C.P.; Lichtman, S.M.; Gajra, A.; Bhatia, S.; Katheria, V.; et al. Predicting chemotherapy toxicity in older adults with cancer: A prospective multicenter study. J. Clin. Oncol. 2011, 29, 3457-3465. [CrossRef]

16. Extermann, M.; Boler, I.; Reich, R.R.; Lyman, G.H.; Brown, R.H.; DeFelice, J.; Levine, R.M.; Lubiner, E.T.; Reyes, P.; Schreiber, F.J.; et al. Predicting the risk of chemotherapy toxicity in older patients: The Chemotherapy Risk Assessment Scale for High-Age Patients (CRASH) score. Cancer 2012, 118, 3377-3386. [CrossRef] [PubMed]

17. Kim, K.H.; Lee, J.J.; Kim, J.; Zhou, J.M.; Gomes, F.; Sehovic, M.; Extermann, M. Association of multidimensional comorbidities with survival, toxicity, and unplanned hospitalizations in older adults with metastatic colorectal cancer treated with chemotherapy. Geriatr. Oncol. 2019, 10, 733-741. [CrossRef] [PubMed]

18. Du, X.L.; Osborne, C.; Goodwin, J.S. Population-based assessment of hospitalizations for toxicity from chemotherapy in older women with breast cancer. J. Clin. Oncol. 2002, 20, 4636-4642. [CrossRef]

19. Reed, M.; Patrick, C.; Quevillon, T.; Walde, N.; Voutsadakis, I.A. Prediction of hospital admissions and grade 3-4 toxicities in cancer patients 70 years old and older receiving chemotherapy. Eur. J. Cancer Care 2019, 28, e13144. [CrossRef] [PubMed]

20. Lichtman, S.M. Chemotherapy in the elderly. Sem. Oncol. 2004, 31, 160-174. [CrossRef] [PubMed]

21. Merrill, C. Elixhauser A: Hospitalization in the United States; Agency for Healthcare Research and Quality: Rockville, MD, USA, 2005. 
22. Li, D.; Sun, C.L.; Kim, H.; Chung, V.; Koczywas, M.; Fakih, M.; Chao, J.; Chien, L.; Charles, K.; Dos Santos Hughes, S.F.; et al. Geriatric assessment-driven intervention (GAIN) on chemotherapy toxicity in older adults with cancer: A randomized controlled trial. J. Clin. Oncol. 2020, 38. [CrossRef]

23. Landrum, L.; Weinrich, S. Readmission Data for Outcomes Measurement: Identifying and Strengthening the Empirical Base. $Q$. Manag. Health Care 2006, 15, 83-95. [CrossRef] [PubMed]

24. Charlson, M.E.; Pompei, P.; Ales, K.L.; MacKenzie, C.R. A new method of classifying prognostic comorbidity in longitudinal studies: Development and validation. J. Chronic Dis. 1987, 40, 373-383. [CrossRef]

25. Roila, F.; Lupattelli, M.; Sassi, M.; Basurto, C.; Bracarda, S.; Picciafuoco, M.; Boschetti, E.; Milella, G.; Ballatori, E.; Tonato, M.; et al. Intra and interobserver variability in cancer patients' performance status assessed according to Karnofsky and ECOG scales. Ann. Oncol. 1991, 2, 437-439. [CrossRef] [PubMed]

26. Guralnik, J.M.; Simonsick, E.M.; Ferruci, L.; Glynn, R.J.; Berkman, L.F.; Blazer, D.G.; Scherr, P.A.; Wallace, R.B. A short physical performance battery assessing lower extremity function: Association with self-reported disability and prediction of mortality and nursing home admission. J. Gerontol. 1994, 49, 85-94. [CrossRef] [PubMed]

27. Guralnik, J.M.; Ferruci, L.; Simonsick, E.M.; Salive, M.E.; Wallace, R.B. Lower-extremity function in persons over the age of 70 years as a predictor of subsequent disability. NEJM 1995, 332, 556-561. [CrossRef]

28. Pfeiffer, E. A short portable mental status questionnaire for the assessment of organic brain deficits in elderly patients. J. Am. Geriatr. Soc. 1975, 22, 433-441. [CrossRef]

29. Katz, S.; Ford, A.B.; Moskowitz, R.W.; Jackson, B.A.; Jaffe, M.W. Studies of illness in the aged: The index of ADL-A standardized measure of biological and psychosocial function. JAMA 1963, 185, 914-919. [CrossRef]

30. Lawton, M.P.; Brody, E.M. Assessment of older people: Self-maintaining and instrumental activities of daily living. Gerontologist 1969, 9, 179-186. [CrossRef]

31. Zigmond, A.S.; Snaith, R.P. The hospital anxiety and depression scale. Acta Psychiatr. Scand. 1983, 67, 361-370. [CrossRef]

32. Ren, X.S.; Skinner, K.; Lee, A.; Kazis, L. Social support, social selection and self-assessed health status: Results from the veterans health study in the United States. Soc. Sci. Med. 1999, 48, 1721-1734. [CrossRef]

33. Costa-Requena, G.; Salamero, M.; Gil, F. Validity of the questionnaire MOS-SSS of social support in neoplastic patients. Med. Clin. 2007, 128, 687-691.

34. Cockcroft, D.W.; Gault, M.H. Prediction of creatinine clearance from serum creatinine. Nephron 1976, 16, 31-41. [CrossRef] [PubMed]

35. Extermann, M.; Chen, H.; Cantor, A.B.; Corcoran, M.B.; Meyer, J.; Grendys, E.; Cavanaugh, D.; Antonek, S.; Camarata, A.; Haley, W.E.; et al. Predictors of tolerance to chemotherapy in older cancer patients: A prospective pilot study. Eur. J. Cancer 2002, 38, 1466-1473. [CrossRef]

36. Hosmer, D.W.; Lemeshow, S. (Eds.) Applied Logistic Regression; John Wiley and Sons: New York, NY, USA, 1989.

37. Hanley, J.A.; McNeil, B.J. The meaning and use of the area under a receiver operating characteristic (ROC) curve. Radiology 1982, 143, 29-36. [CrossRef]

38. Concato, J.; Feinstein, A.R.; Holford, T.R. The risk of determining risk with multivariable models. Ann. Intern. Med. 1993, 118, 201-210. [CrossRef]

39. Hastie, T.; Tibshirani, R.; Friedman, J. (Eds.) The Elements of Statistical Learning: Data Mining, Inference, and Prediction, 2nd ed.; Springer: New York, NY, USA, 2009. 